\title{
Thermochemistry of $\mathrm{MgB}_{2}$ Thin Film Synthesis
}

\author{
Jihoon Kim, Rakesh K. Singh, Nathan Newman, and John M. Rowell
}

\begin{abstract}
We have investigated the thermodynamic and kinetic barriers involved in the synthesis of $\mathrm{MgB}_{2}$ films. This work refines our initial conjectures predicting optimal $\mathrm{MgB}_{2}$ thin film growth conditions as a consequence of the unusually large kinetic barrier to $\mathrm{MgB}_{2}$ decomposition. The small $\mathrm{Mg}$ sticking coefficient at temperatures greater than $300^{\circ} \mathrm{C}$ prevents high temperature synthesis with traditional vacuum growth methods. However, as a result of the large kinetic barrier to $\mathrm{MgB}_{2}$ decomposition, insitu thermal processing can be used to enhance the crystallinity and the superconductivity of $\mathrm{MgB}_{2}$ films. We used these methods to produce $\mathrm{MgB}_{2}$ thin films with relatively high transition temperatures $(\sim 37 \mathrm{~K})$ by pulsed laser deposition (PLD).
\end{abstract} films.

Index Terms- $\mathrm{MgB}_{2}$, Superconductor, Thermochemistry, Thin

\section{INTRODUCTION}

A transition temperature $\mathrm{Tc}$ of $39 \mathrm{~K}[1]$ makes $\mathrm{MgB}_{2}$ an attractive candidate material for use in digital superconducting circuits operating at temperatures up to $25 \mathrm{~K}$, as well as in a number of other superconducting applications. The first step in the development of a technology for all electronics applications is the synthesis of thin films of $\mathrm{MgB}_{2}$ with properties as close as possible to those of the best bulk samples. Ideally, it would be preferable to develop an asmade in-situ or one-step in-situ deposition process, i.e., one in which there is no anneal following the deposition. It has become clear that $\mathrm{MgB}_{2}$ film synthesis strikingly illustrates the importance of understanding and controlling the condensation and desorption of the $\mathrm{Mg}$ and $\mathrm{B}$ species (which define their sticking coefficients), their surface diffusion and nucleation, bulk diffusion, and the $\mathrm{MgB}_{2}$ phase formation (and the formation of competing phases, including impurity phases such as $\mathrm{MgO}$ ), as well as decomposition at both the growth temperature and at post-anneal temperatures, if such anneals are used. In this paper, we will describe our present

Manuscript received August 6, 2002. This work was supported by the Office of Naval Research (Contract No. N00014-02-1-0002).

J. Kim is with the Chemical and Materials Engineering Department, Arizona State University, Tempe, AZ 85287 USA (phone: 480-727-6934; fax: 480-965-0037; e-mail: Jihoon.Kim@asu.edu).

R. K. Singh is with the Chemical and Materials Engineering Department, Arizona State University, Tempe, AZ 85287 USA. (e-mail: Rakesh.K.Singh@asu.edu).

N. Newman is with the Chemical and Materials Engineering Department, Arizona State University, Tempe, AZ 85287 USA. (email:Nathan.Newman@asu.edu).

J. M. Rowell is with Northwestern University, Evanston, IL 60208 and visiting Professor, Arizona State University, Tempe, AZ 85287 USA. (email:jmrberkhts@aol.com). understanding of these issues, and we will illustrate many of them by presenting the results of our own film growth studies.

\section{EXPERIMENTAL METHOD}

Our deposition system is built to ultra high vacuum specifications but so far has not been baked to improve its background pressure. It is pumped by a cryopump (CTI model 8 ). Before deposition, the typical pressure is $10^{-8}$ torr, during deposition it rises to $\sim 10^{-7}$ torr. Deposition of the $\mathrm{B}$ is by laser ablation from a B target of $99.9 \%$ purity. A $248 \mathrm{~nm} \mathrm{KrF}$ excimer laser is used at a repetition rate of $8 \mathrm{~Hz} . \mathrm{Mg}$ is evaporated from a Knudsen cell through a $2.5 \mathrm{~cm}$ diameter 25 $\mathrm{cm}$ long cylindrical cryoshroud cooled by liquid nitrogen. The flux of $\mathrm{B}$ and $\mathrm{Mg}$ is measured with a water-cooled quartz crystal monitor. $1 \mathrm{~cm}^{2}$ sapphire substrates are fixed with silver paste to a resistively heated substrate that can reach $900^{\circ} \mathrm{C}$. Electrical properties were characterized using a dipping probe with spring loaded contacts. The thickness of the films, and their composition, was determined by the routine use of Rutherford Backscattering.

\section{RESULTS AND DISCUSSION}

\section{A. Evaporation of $\mathrm{Mg}$ from $\mathrm{Mg}$}

The vapor pressure of $\mathrm{Mg}$ over $\mathrm{Mg}$ metal is taken from tables and is reproduced in Fig. 1. We have also included another scale that shows the evaporation rate, in Angstroms per second. As is well known, $\mathrm{Mg}$ has extremely high vapor pressures at relatively low temperatures, for example $10^{-7}$ torr at $210^{\circ} \mathrm{C}$, increasing to 1 torr at $600^{\circ} \mathrm{C}$. As the melting point of $\mathrm{Mg}$ is $649^{\circ} \mathrm{C}$, generally $\mathrm{Mg}$ vapor sublimes from the solid, rather than evaporating from the melt. To illustrate the implication of such high $\mathrm{Mg}$ vapor pressures for $\mathrm{MgB}_{2}$ growth, let us assume that we wish to grow an $\mathrm{MgB}_{2}$ film of thickness $2000 \AA$ in a deposition time of 20 minutes, or at a deposition rate of $6000 \AA$ /hour, or $1.7 \AA /$ s. We can see in Fig. 1 that, if the substrate temperature is $270^{\circ} \mathrm{C}, \mathrm{Mg}$ will be lost at this rate. Hence, unless $\mathrm{Mg}$ reacts rapidly with $\mathrm{B}$ to form $\mathrm{MgB}_{2}$ at this temperature, there will be no net accumulation of $\mathrm{Mg}$ on the substrate at this or at higher temperatures, unless the $\mathrm{Mg}$ incorporation rate (i.e. product of impinging flux and sticking coefficient) is above $1.7 \AA / \mathrm{s}$.

\section{B. Evaporation of $\mathrm{Mg}$ from $\mathrm{MgB}_{2}$}

Given the known high vapor pressures of $\mathrm{Mg}$ over $\mathrm{Mg}$ metal, it seemed important to us early in 2001 to determine the vapor pressure of $\mathrm{Mg}$ over $\mathrm{MgB}_{2}$, and hence the evaporation rate of $\mathrm{Mg}$ from $\mathrm{MgB}_{2}$. The higher this evaporation rate, the more difficult it is to attain useful growth rates at substrate 
temperatures which form a well ordered crystalline phase. Our measurements of the $\mathrm{Mg}$ vapor pressure over a bulk source of $\mathrm{MgB}_{2}$ were reported earlier[2] and the results are presented in Fig. 1. For comparison, we also show the expected vapor pressure calculated by Z.-K. Liu et al from the thermodynamics of the $\mathrm{MgB}_{2}$ system[3]. It is immediately clear that the vapor pressure we measured is significantly lower than that expected thermodynamically, by a factor of over $10^{3}$. This small evaporation coefficient of $\mathrm{MgB}_{2}$ implies, for example, that if a growth temperature of $650^{\circ} \mathrm{C}$ is selected, the loss of $\mathrm{Mg}$ from the compound film will be at a rate of 1 monolayer/second, whereas $10^{3}$ monolayers/second, or about $3,000 \AA /$ second, would have been expected from thermodynamic considerations alone.

\section{Sticking probability of $M g$}

We can study the sticking probability of $\mathrm{Mg}$ and $\mathrm{B}$ by reference to the results of our as-made film growth studies, which are summarized in Fig. 2(a). Depositions were made at a flux of $\mathrm{Mg}$, set by the quartz crystal monitors at $1 \AA / \mathrm{sec}$. At $\mathrm{T}_{\mathrm{dep}}=150^{\circ} \mathrm{C}$, we obtained a film thickness of $2100 \AA$ for a deposition of 40 minutes, or a deposition rate of $\sim 3200$ $\AA /$ hour. At $200^{\circ} \mathrm{C}$, this deposition rate has dropped to $800 \AA$ /hour, and at $250^{\circ} \mathrm{C}$ to $400^{\circ} \mathrm{C}$ it is in the range of 200 to $300 \AA$ hour, for the same incident $\mathrm{Mg}$ flux. The film stoichiometry also changes with $\mathrm{T}_{\text {dep }}$, as shown in Fig. 2(b). At $150^{\circ} \mathrm{C}$, the $\mathrm{Mg}: \mathrm{B}$ ratio is about $1.3: 2$, at 200 and $250^{\circ} \mathrm{C}$ it is very close to $1: 2$, at 300 and $350^{\circ} \mathrm{C}$ it has dropped to about $1: 4$, while at $400^{\circ} \mathrm{C}$ it is about $1: 5$. The rapid decrease in thickness shows that, for temperatures above $250^{\circ} \mathrm{C}$, the film growth rate has declined to less than one tenth of its value at $150^{\circ} \mathrm{C}$. We have already shown that this is not due to the decomposition of fully reacted $\mathrm{MgB}_{2}$. Rather, it is due to a very low sticking probability of $\mathrm{Mg}$ onto the substrate and onto the deposited $\mathrm{B}$. The sticking coefficients of $\mathrm{Mg}$ depending on temperature and flux are shown on Fig. 2(a). Above $200^{\circ} \mathrm{C}$, the $\mathrm{Mg}$ sticking coefficient becomes lowered to less than 0.17 , from 0.74 at $150^{\circ} \mathrm{C}$, when the $\mathrm{Mg}$ flux is 1 $\AA /$ sec. Though higher flux rate surely enhances the sticking coefficient at the same temperature, the increase in the sticking coefficient at higher flux becomes less at higher temperatures. On the other hand, boron shows no change in its sticking coefficient as temperature changes. These results illustrate the key problem in $\mathrm{MgB}_{2}$ film growth in high vacuum, namely that low sticking probabilities imply that there is only a small probability that $\mathrm{Mg}$ reacts with $\mathrm{B}$ to form a non-volatile $\mathrm{Mg}-\mathrm{B}$ complex (e.g. $\mathrm{MgB}_{2}$ ) on the surface. Therefore, very little film growth is accomplished above $200^{\circ} \mathrm{C}$, unless the $\mathrm{Mg}$ flux is increased to very high levels to enhance the reaction probability with the surface B species. Fig. 2 shows that enhanced $\mathrm{Mg}$ rates result in increases in the $\mathrm{Mg}: \mathrm{B}$ ratio to over 1:2, as well as the Tcs. The enhanced rate of $\mathrm{Mg}$, which is almost certainly the faster diffusing species on the growth surface, would be expected to enhance the effective surface diffusion rate, analogous to group-III rich growth in III-N MBE growth, as well as to help drive the synthesis reaction. Therefore enhanced $\mathrm{Mg}$ rates would presumably lead to improved $\mathrm{MgB}_{2}$ crystallinity and higher Tcs, as is experimentally found. Our findings are also consistent with the formation of a high-resistive non-superconducting metastable phase for sub-stoichiometric $\mathrm{MgB}_{2}$ compounds [4].

For temperatures greater than $\sim 220^{\circ} \mathrm{C}$, when the evaporation rate from $\mathrm{Mg}$ is greater than the $\mathrm{Mg}$ incorporation rate (left of the intersection of these curves in fig. 1), the $\mathrm{Mg}$ remaining in the film must exist in non-volatile $\mathrm{Mg}$-B compounds. Note that the sticking coefficient exhibits a measurable and gradual drop at temperatures higher than where all the $\mathrm{Mg}$ metal would have been desorbed (i.e. $>\sim 240^{\circ} \mathrm{C}$ ), but lower than where significant $\mathrm{MgB}_{2}$ decomposition begins. This indicates that $\mathrm{Mg}$ must form an intermediate $\mathrm{Mg}-\mathrm{B}$ chemisorbed species with a bond strength that falls between that of $\mathrm{Mg}$ metal and fully reacted $\mathrm{MgB}_{2}$ compounds.

\section{D. $\mathrm{MgB}_{2}$ phase formation}

An approximate rule of thumb, often used to estimate the substrate temperatures required to develop high-quality epitaxial films, is that the deposition temperature should be between one half and two thirds of the melting point. As $\mathrm{MgB}_{2}$ melts at $2700 \mathrm{~K}$, this would mean that films should be grown at temperatures above $1000^{\circ} \mathrm{C}$. Fortunately, many films grow highly-oriented, and even epitaxial, at much lower temperatures, and this is the case for $\mathrm{MgB}_{2}$. Ueda and Naito[5] showed that films with $\mathrm{Tc}_{\text {onset }}$ and $\mathrm{Tc}_{\mathrm{zero}}$ of $12.2 \mathrm{~K}$ and $5.2 \mathrm{~K}$, respectively, could be made by growth at $150^{\circ} \mathrm{C}$. [Henceforth, we use $12.2 / 5.2 \mathrm{~K}$, to denote $\mathrm{Tc}_{\text {onset }} / \mathrm{Tc}_{\mathrm{zero}}$.] Our films at $150^{\circ} \mathrm{C}$ were not superconducting, but at $200^{\circ} \mathrm{C}$ the Tc was $13.9 / 12.4 \mathrm{~K}$ for our as-made films produced with the higher $\mathrm{Mg}$ impingement rate $(1.5 \AA / \mathrm{s})$. It is interesting to note that films deposited at 200 and $250^{\circ} \mathrm{C}$ with a $\mathrm{Mg}: \mathrm{B}$ impinging flux ratio of $1: 2$ (i.e. a $\mathrm{Mg}$ flux of $1 \AA$ /s) did not exhibit superconductivity, presumably as a result of poor crystallization and small grain size.

Our results, and those of Ueda and Naito, indicate that substrate temperatures of only 150 to $200^{\circ} \mathrm{C}$ are adequate to produce some $\mathrm{MgB}_{2}$ phase in the film. Whether such low deposition temperatures can result in well-ordered films, with resistivities comparable to low bulk values $(10 \mu \Omega-\mathrm{cm}$ at $300 \mathrm{~K})[6]$, remains to be seen. Determination of the resistivity of as-made films is sometimes affected by the presence of excess unreacted $\mathrm{Mg}$. In our deposition system, we can view the film at it is growing. Films made at $\sim 200-225^{\circ} \mathrm{C}$ appear matt and gray, but on annealing above $500^{\circ} \mathrm{C}$, quite quickly become highly reflective. We believe this is a direct observation of the evaporation of excess $\mathrm{Mg}$. Thus it is likely that resistivity measurements of films made at relatively low temperatures can be affected by excess $\mathrm{Mg}$.

\section{E. Temperature window for in-situ film growth}

We can summarize our discussion of the constraints on $\mathrm{MgB}_{2}$ film growth in vacuum. The small sticking probability of $\mathrm{Mg}$ at temperatures above $325^{\circ} \mathrm{C}$ limits the deposition temperature to the range below this value, unless the $\mathrm{Mg}$ flux is increased to extremely high values. Below $300^{\circ} \mathrm{C}$, the crystalline order of $\mathrm{MgB}_{2}$ appears to be limited. The decomposition of $\mathrm{MgB}_{2}$, and the evaporation of $\mathrm{Mg}$ from $\mathrm{MgB}_{2}$, limits anneal temperatures in vacuum to temperatures below about $850^{\circ} \mathrm{C}$. Consideration of these constraints defines 
the various modes of $\mathrm{MgB}_{2}$ film growth: (a) As-made growth at temperatures below $325^{\circ} \mathrm{C}$, (b) As-made growth at temperatures above $325^{\circ} \mathrm{C}$ with high $\mathrm{Mg}$ fluxes in vacuum, (c) As-made growth at temperatures above $325^{\circ} \mathrm{C}$ by processes employing high $\mathrm{Mg}$-containing gas pressures, such as MOCVD, (d) Deposition at temperatures below $325^{\circ} \mathrm{C}$, followed by an in-situ anneal at high temperatures typically in a high pressure of inert gas.

\section{F. Growth of $\mathrm{MgB}_{2}$ films - as-made, heat-cycle, and in-situ post anneal.}

We have grown $\mathrm{MgB}_{2}$ films by three processes - as-made, by what we term a heat cycle process, and using an in-situ postanneal in argon.

(a) As-made (single step growth): Using an as-made process, we were successful in obtaining superconducting films at deposition temperatures of $200^{\circ} \mathrm{C}(13.9 / 12.4 \mathrm{~K})$ and at $225^{\circ} \mathrm{C}$ (14.3/11.7K). To obtain superconducting films, our incident flux of $\mathrm{Mg}$ was increased to $1.5 \AA / \mathrm{sec}$ at $200^{\circ} \mathrm{C}$, and to $3 \AA / \mathrm{sec}$ at $225^{\circ} \mathrm{C}$. Our RBS measurements show that the $\mathrm{Mg}: \mathrm{B}$ composition is close to $1: 2$ up to $250^{\circ} \mathrm{C}$. Fig. 1 shows the decrease in the growth rate due to the diminishing $\mathrm{Mg}$ sticking coefficient. However, there was no significant decomposition during the single step process. The growth rate is orders of magnitude faster than the $\mathrm{MgB}_{2}$ decomposition rate in this low temperature range as a result of the relatively low growth temperature.

(b) Heat-cycle process: This process was an attempt to simulate a series of in-situ thermal anneals on effectively thin layers. The films were grown following a cycle of 10 minutes of deposition at a substrate deposition temperature $\left(\mathrm{T}_{\mathrm{dep}}\right)$ of $\sim 200^{\circ} \mathrm{C}-225^{\circ} \mathrm{C}$, followed by increasing the substrate temperature to a higher ultimate temperature, designated $\mathrm{T}_{\max }$, at a ramp rate of about $120^{\circ} \mathrm{C} /$ minutes. As soon as $\mathrm{T}_{\max }$ was reached, the heater current was decreased, and the temperature returned to $\mathrm{T}_{\mathrm{dep}}$ at about $40^{\circ} \mathrm{C} /$ minutes. This cycle was repeated 5 times, with the $\mathrm{Mg}$ and $\mathrm{B}$ fluxes remaining fixed. We hoped that the $\mathrm{MgB}_{2}$ phase would form at the relatively low deposition temperature, and that crystalline order would be enhanced during the cycle to higher anneal temperatures, without loss of $\mathrm{Mg}$ from the $\mathrm{MgB}_{2}$, as the values of $\mathrm{T}_{\max }$ were kept below $600^{\circ} \mathrm{C}$. Tcs of these heat-cycle films are shown in Fig. 3 and Fig. 5(a). This figure reveals the following trends. The film thickness, which is $1750 \AA$ for the initial deposition at $200^{\circ} \mathrm{C}$ (with excess $\mathrm{Mg}$ ), decreases steadily as $\mathrm{T}_{\max }$ increases, dropping to about $500 \AA$ for $\mathrm{T}_{\max }=550^{\circ} \mathrm{C}$. During the cycled growth, 50 minutes is spent at $200^{\circ} \mathrm{C}$, and, as the films are superconducting as-made at $200^{\circ} \mathrm{C}$, clearly some $\mathrm{MgB}_{2}$ phase must be formed. For temperatures above $\sim 250^{\circ} \mathrm{C}$, all of the free $\mathrm{Mg}$ should be desorbed. Significant amounts of additional $\mathrm{Mg}$ should not be lost from $\mathrm{MgB}_{2}$ until we reach $\mathrm{T}_{\max }$ of more than $500^{\circ} \mathrm{C}$. Perhaps much of the film at $250^{\circ} \mathrm{C}$ and higher must still be in the form of an intermediate $\mathrm{Mg}-\mathrm{B}$ chemisorbed species, which is lost during the thermal cycles. Clearly, the bond strength of this species must fall between the relatively strongly bound $\mathrm{MgB}_{2}$ and the weakly bound free $\mathrm{Mg}$ metal. Overall, the Mg:B stoichiometry falls at or below 1:2. It is also possible that $\mathrm{Mg}$-rich regions with species such as free
$\mathrm{Mg}$ or $\mathrm{Mg}_{3} \mathrm{~B}_{2}$ are buried below the surface and therefore only susceptible to desorption after exposure to sufficient time and temperature. However, we find, that by comparing the chemical composition of films exposed to a number of heats cycles, with a single anneal (as described in the next section), that the influence of this effect is not the rate-limiting step.

The Mg:B stoichiometry, which is over $1: 1$ at $200^{\circ} \mathrm{C}$, also drops, becoming $1: 2$ at $\mathrm{T}_{\max }=300$ and $350^{\circ} \mathrm{C}$, but only $1: 4$ at $550^{\circ} \mathrm{C}$. Figure 5 illustrates the electrical properties of the films as a function of temperature. The Tc, which is $13.9 / 12.4 \mathrm{~K}$ without any anneal, drops to $10.0 / 6.0 \mathrm{~K}$ for $\mathrm{T}_{\max }$ of $300^{\circ} \mathrm{C}$, then slowly increases to $21.0 / 14.4 \mathrm{~K}$ at $\mathrm{T}_{\max }$ of $550^{\circ} \mathrm{C}$. The high resistivities (factor of 10 and higher) yet similar form of the temperature dependence of the resistivity, when compared to low resistivity bulk samples[6], presumably indicates that these films form a loosely connected network of superconducting regions with reduced effective cross-sectional area. The reduced Tc indicates that these films are in the dirty limit as a result of poor crystallinity and/or small grain sizes.

(c) In-situ post-anneal: Our in-situ anneal process begins with a similar deposition at $225^{\circ} \mathrm{C}$. As soon as the deposition is complete, the chamber is filled with 10 torr argon, and the heater temperature is increased to an ultimate temperature, $\mathrm{T}_{\max }$. In some cases, the heater power was turned off as soon as $\mathrm{T}_{\max }$ was reached, in other cases the anneal temperature was maintained for times as long as 30 minutes. The properties of our in-situ post-annealed films are summarized in Fig. 4 and Fig. 5. As we noted earlier, the films made at $225^{\circ} \mathrm{C}$ have excess $\mathrm{Mg}$ and are nearly $2000 \AA$ thick. As the anneal temperature is increased, the thickness drops as free $\mathrm{Mg}$ or weakly bound $\mathrm{Mg}$ evaporates away, and is in the range between 250 and $550 \AA$ for all the annealed films. The Mg:B stoichiometry is $1: 2$ for $\mathrm{T}_{\max }$ from 650 to $750^{\circ} \mathrm{C}$, then drops to $1: 2.5$ by $850^{\circ} \mathrm{C}$. The transition temperatures of the films are increased substantially by the anneals. We note that using our heat-cycle process to $550^{\circ} \mathrm{C}$, we only achieved a $\mathrm{Tc}$ of 21.0/14.4K. However, the post anneal in argon yields films with $\mathrm{Tcs}$ of $27.5 / 25.5 \mathrm{~K}$ if a $\mathrm{T}_{\max }$ of $550^{\circ} \mathrm{C}$ is maintained for only 10 seconds, whereas $33.5 / 31.5 \mathrm{~K}$ results from an anneal at $550^{\circ} \mathrm{C}$ for 30 minutes. For short anneals, the maximum Tcs are achieved at 750 and $800^{\circ} \mathrm{C}$, being 35/33.5K. Fig. 6 shows the decomposition rates during heat-cycle and post-anneal processes. The figure clearly illustrates similar net $\mathrm{Mg}$ loss occurs for both processes, at least at the common thermal processing temperature of $550^{\circ} \mathrm{C}$. Our studies clearly show that a single post-anneal results in higher quality films and higher Tcs than the multiple step heat cycling. It appears that the single annealing step process on the thicker layers and the heat cycling process on effectively thinner layers result in similar chemical stoichiometries for similar annealing temperatures and total times. The role of the thicker layers appears to produce improved electrical properties via improved crystalinity and grain size. TEM studies are in progress to experimentally determine the resulting differences in microstructure.

This post anneal scheme was also applied to various substrates such as $\mathrm{MgO}, \mathrm{AlN}(2000 \AA) / \mathrm{SiC}$, etc. These films were grown with the same condition, deposition at $225^{\circ} \mathrm{C}$ and 
anneal at $700^{\circ} \mathrm{C}$ for 1 minute. Fig. 5 includes a $37 \mathrm{~K} \mathrm{Tc}_{\text {onset }}$ of the film grown on an AlN buffer layer. We will publish details of the role that the substrate has on the chemical and electrical properties of $\mathrm{MgB}_{2}$ thin films in a future publication.

\section{CONCLUSION}

The small $\mathrm{Mg}$ sticking coefficient limits the initial growth temperature to less than $300^{\circ} \mathrm{C}$ for $\mathrm{MgB}_{2}$ vacuum deposition methods. The large kinetic barriers to the decomposition of $\mathrm{MgB}_{2}$ makes it possible to use in-situ thermal processing at elevated temperatures to synthesize high quality $\mathrm{MgB}_{2}$. With this approach, we have produced $\mathrm{MgB}_{2}$ with $37 \mathrm{~K} \mathrm{Tc}_{\text {onsets }}$ using pulsed laser deposition.

\section{ACKNOLWEDGEMENTS}

We would like to thank Deborah Van Vechten for her encouragement and support, as well as Barry Wilkens for assistance in the RBS measurements and John Kouvetakis and Lei Yu for helpful discussions.

\section{REFERENCES}

[1] J. Nagamatsu, N. Nakagawa, T. Muranaka, Y. Zenitani, and J. Akimitsu, Nature (London) 410, pp. 63, 2001.

[2] Z. Y. Fan, D. G. Hinks, N. Newman, and J. M. Rowell, Appl. Phys. Lett. Vol. 79, No. 1, pp. 87-89, July 2001.

[3] Z. K. Liu, D. G. Schlom, Q. Li, and X. X. Xi, Appl. Phys. Lett. Vol. 78, No. 23, pp. 3678-3680, June 2001.

[4] P.A. Sharma, N. Hur, Y. Horibe C. H. Chen B. G. Kim S. Guha M. Z. Cieplak and S-W. Cheong to be published. Bull. Am. Phys. Soc. 47, 148 abstract B14 4, 2002

[5] K. Ueda and M. Natio, Appl. Phys. Lett. Vol. 79, No. 13, pp. 20462048, Sept 2001.

[6] Yu. Eltsev, S. Lee, K. Nakao, N. Chikumoto, S. Tajima, N. Koshizuka, and M. Marakami, Cond-mat/0201451 $0202133,0204027$. 


\section{Figure Captions}

Fig. 1. Comparison of the $\mathrm{Mg}$ vapor pressure over $\mathrm{Mg}$ metal and $\mathrm{MgB}_{2}$. Comparison is made with thermodynamic predictions of Reference 3. The Mg incorporation rate during PLD growth is found to diminish as elevated temperatures as a result of a reduced sticking coefficient. Note that above $220^{\circ} \mathrm{C}$, the $\mathrm{Mg}$ evaporation rate from metallic $\mathrm{Mg}$ is greater than the $\mathrm{Mg}$ incorporation rate achieved during our PLD growth.

Fig. 2. Growth rate, sticking coefficient, and stoichiometry of $\mathrm{MgB}_{2}$ thin films synthesized with various Mg fluxes by PLD. The reduced sticking Mg coefficient results in the reduced growth rates and $\mathrm{Mg}: \mathrm{B}_{2}$ ratios with increasing temperature.

Fig. 3. Summary of the heat-cycle process, (a) Tc and (b) thickness and stoichiometry of the deposited $\mathrm{MgB}_{2}$ films.

Fig. 4. Summary of the in-situ post-anneal process, (a) Tc and (b) thickness and stoichiometry of the deposited $\mathrm{MgB}_{2}$ films.

Fig. 5. Electrical properties of $\mathrm{MgB}_{2}$ (a) formed by the heat-cycle process on sapphire and (b) formed by the post-anneal process on sapphire and $\mathrm{AlN} / \mathrm{SiC}$ substrates.

Fig. 6. Comparison of rate of $\mathrm{Mg}$ loss during heat-cycle and post-anneal processes to relevant evaporation rates. 


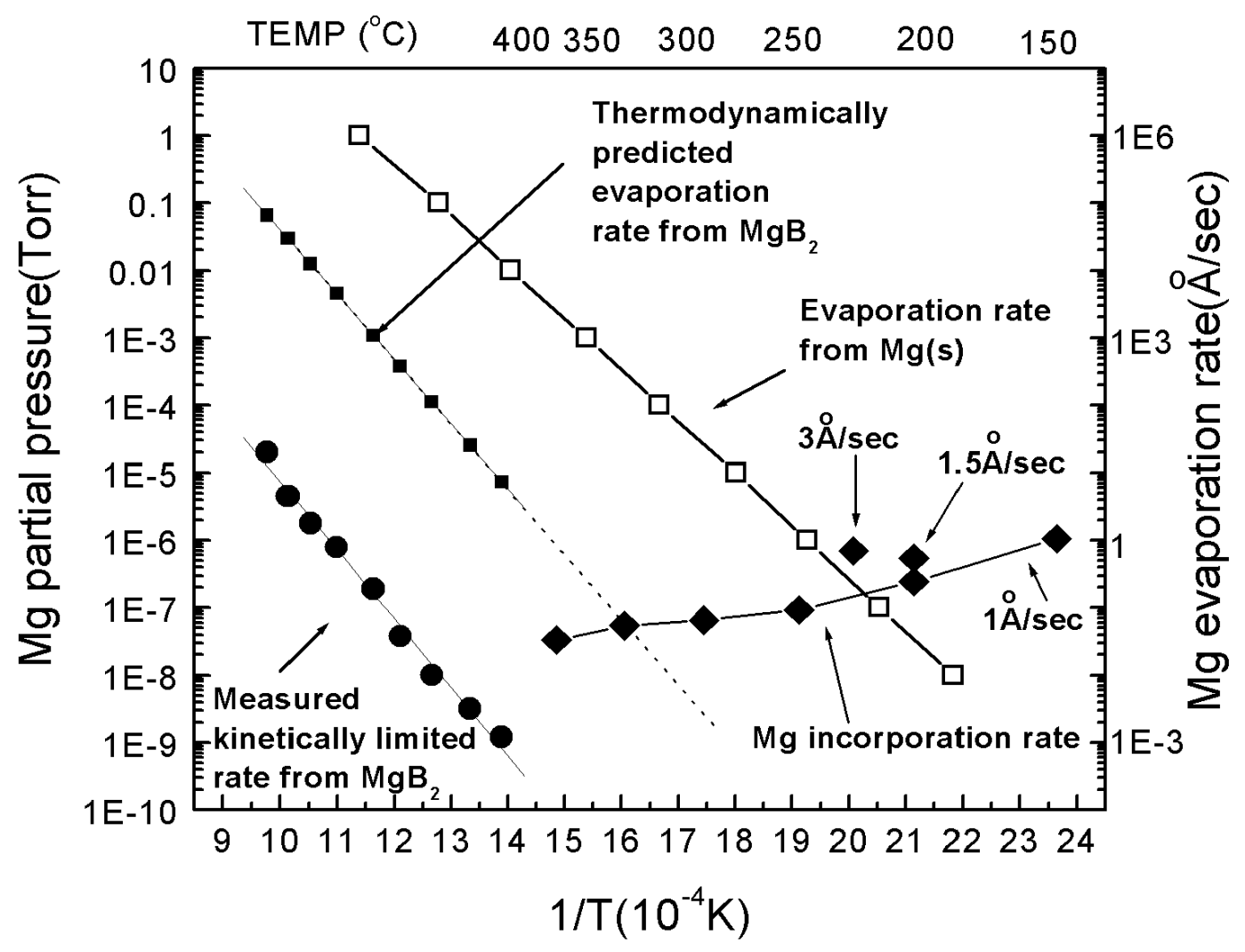

Fig. 1. 

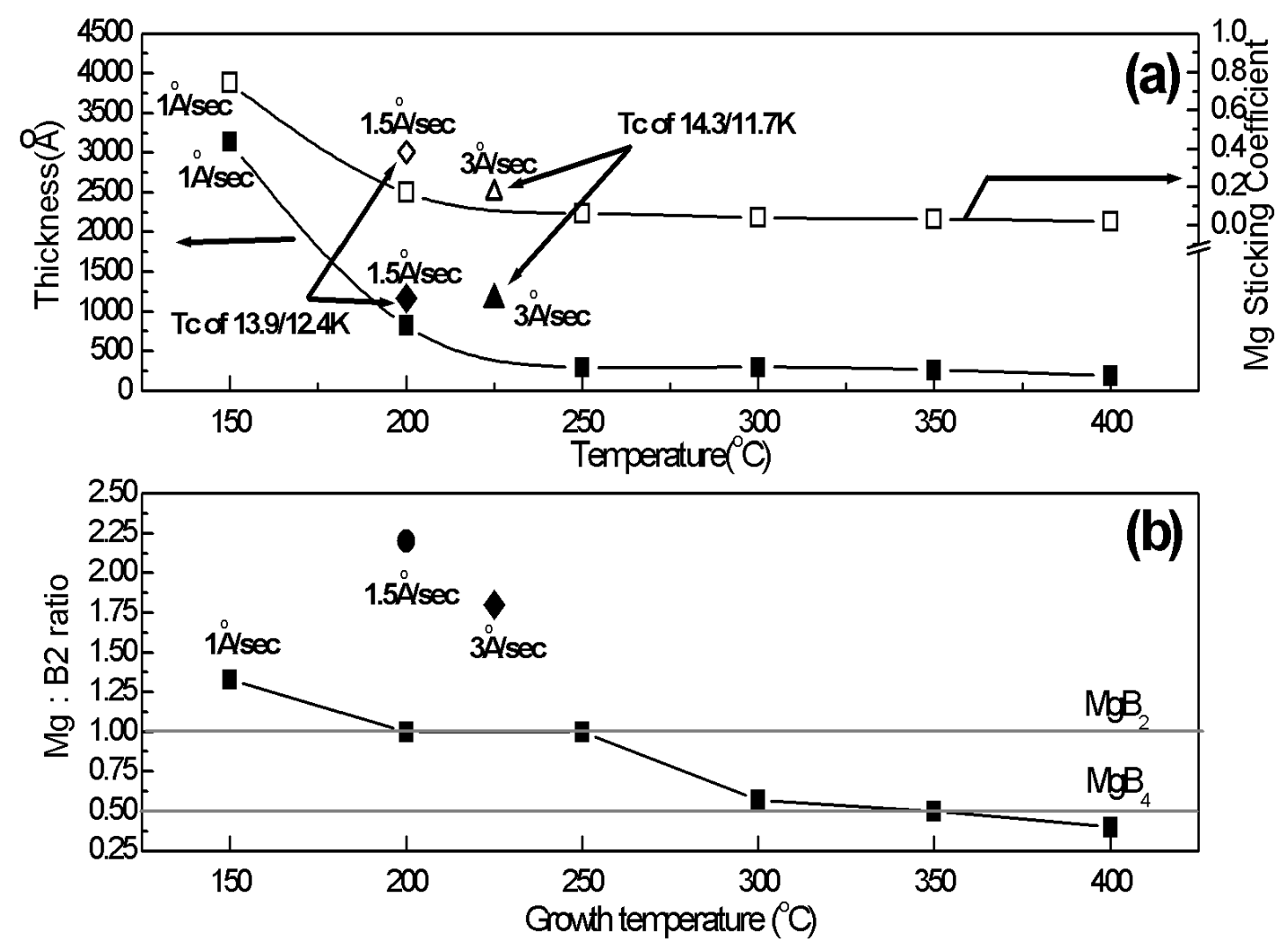

Fig. 2. 

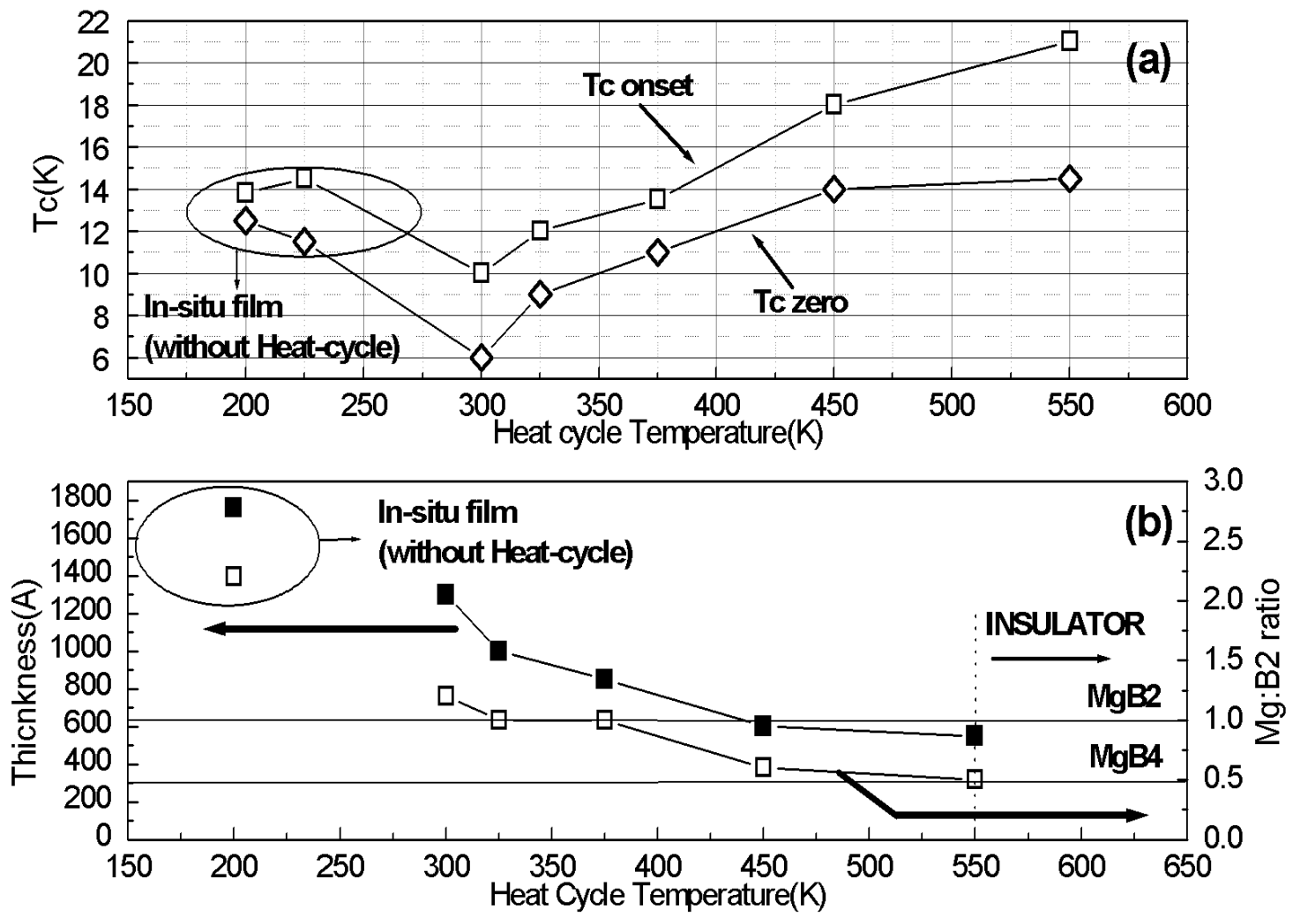

Fig. 3. 

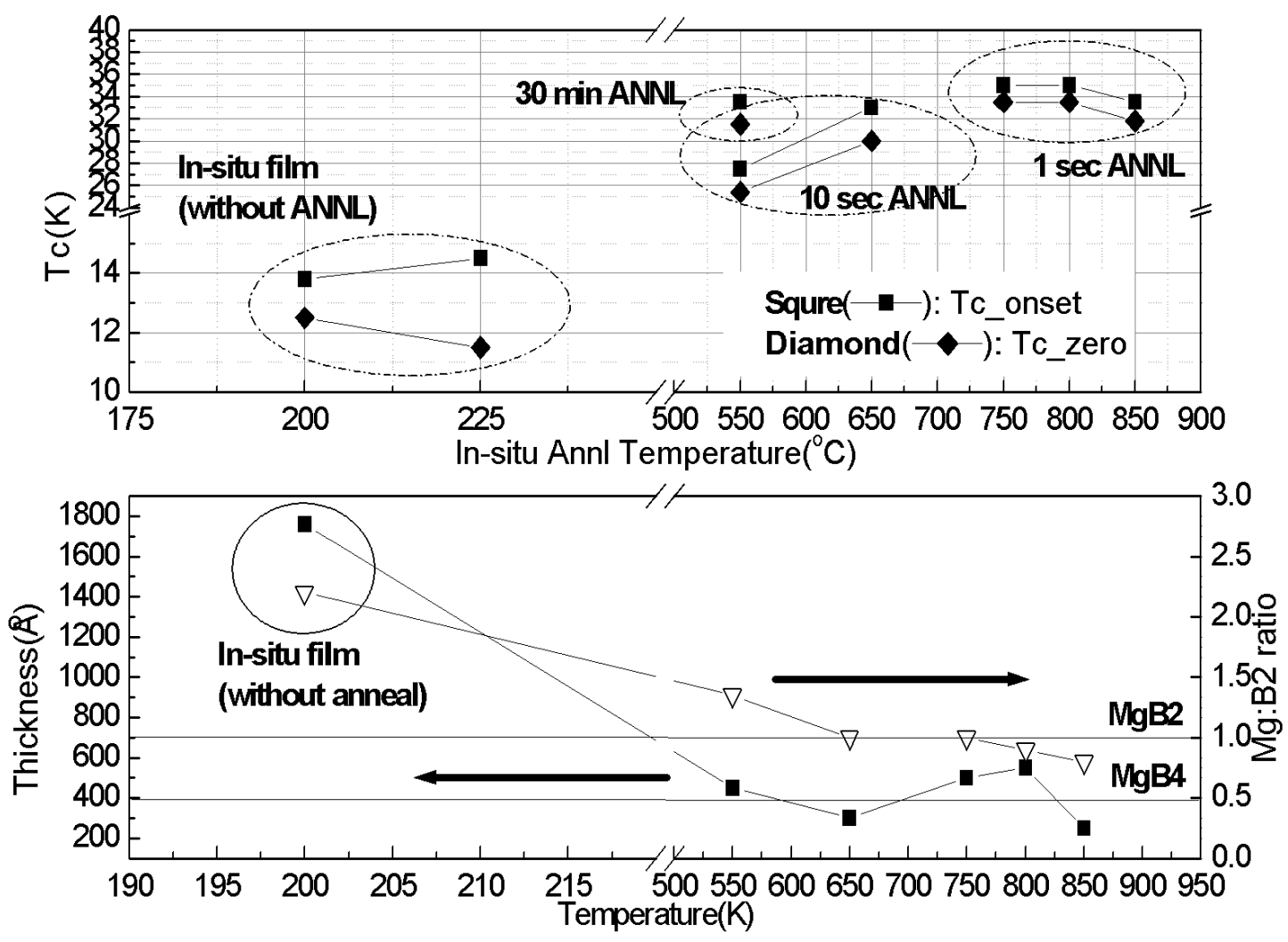

Fig. 4. 

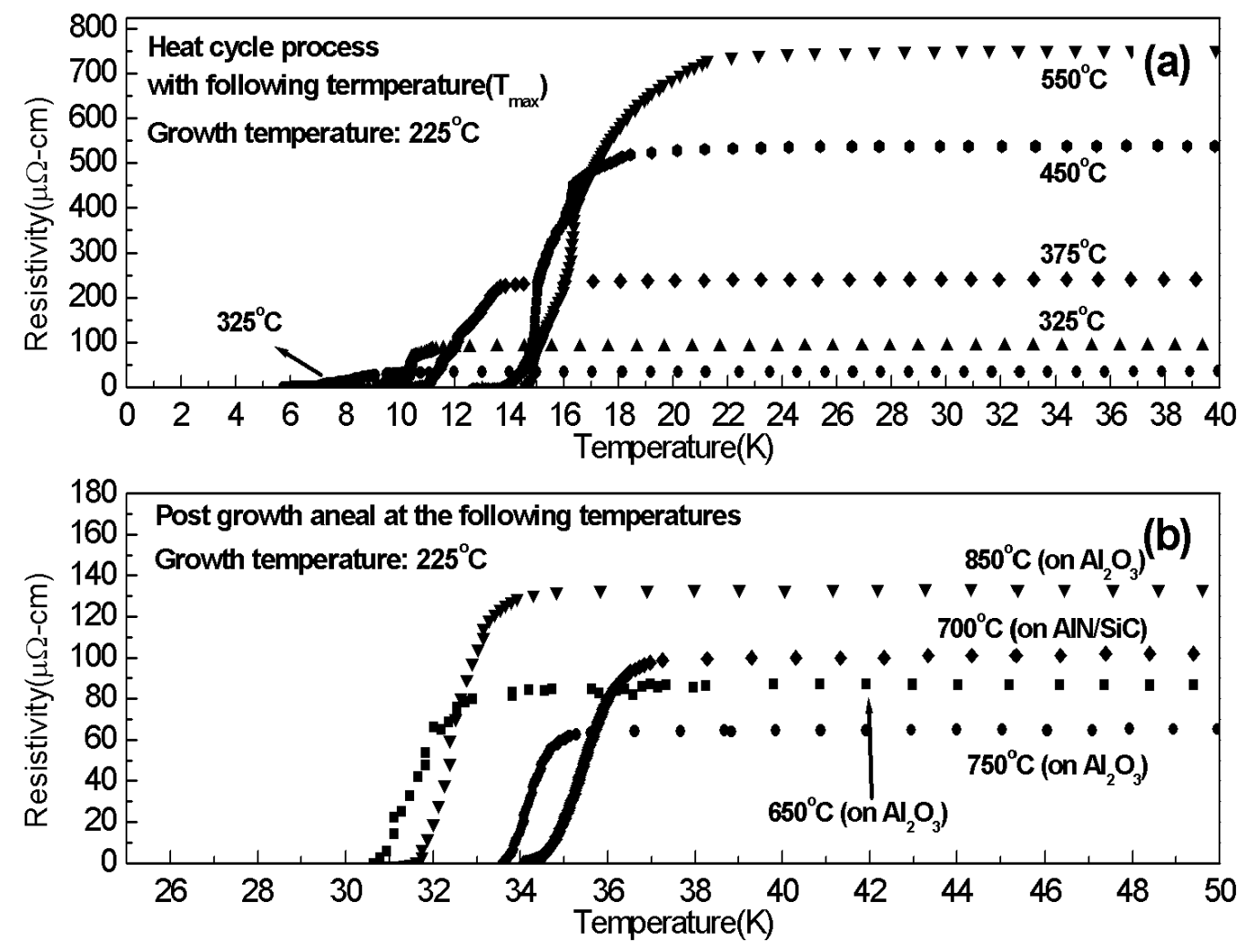

Fig. 5. 


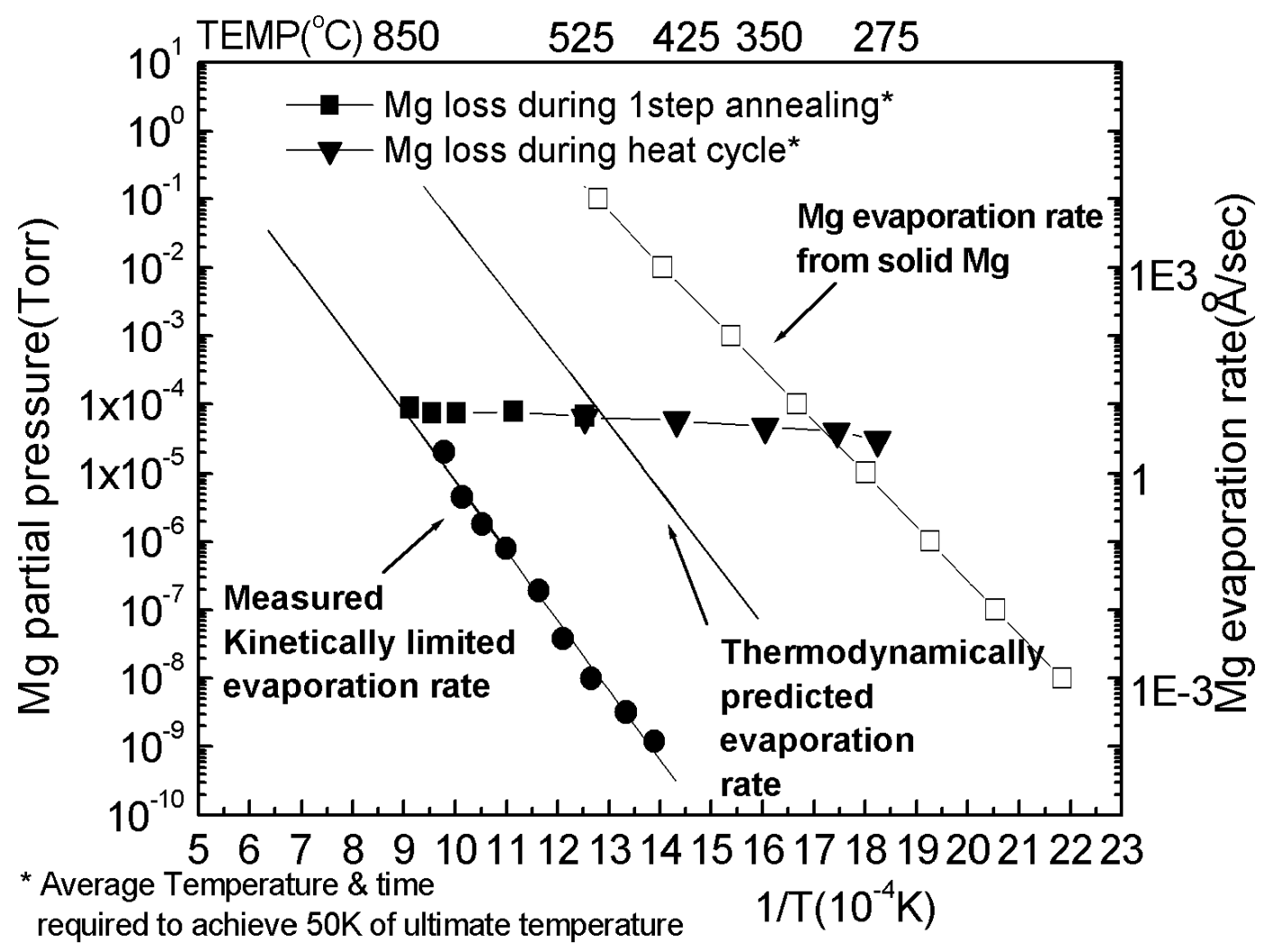

Fig. 6. 